\title{
Is there an Association between Vaginal Cancer and Genital Prolapse? A Data-Analysis and Review of Literature
}

\author{
Heidrun Männle ${ }^{1^{*}}$, Birthe Osorio $^{1}$, Felix Momm ${ }^{2}$ and Karsten Münstedt ${ }^{1}$ \\ ${ }^{1}$ Department of Gynecology and Obstetrics, Ortenau-Klinikum Offenburg-Kehl, Germany \\ ${ }^{2}$ Department of Radio-Oncology, Ortenau-Klinikum Offenburg-Kehl, Weingartenstr, Germany \\ *Corresponding author: Heidrun Männle, Ortenau-Klinikum Offenburg-Kehl, Ebertplatz 12, 77654 \\ Offenburg, Germany, Tel: 0049/781/472-3501, Fax: 0049/781/472-3502
}

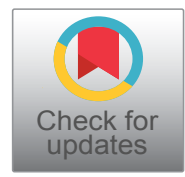

\begin{abstract}
Purpose: Primary vaginal cancer represents a rare disease. The main risk factor for vaginal carcinoma is a persistent human papillomavirus (HPV) infection. However, chronic mechanic irritation of the vagina, have long been suspected to contribute to the development of vaginal cancer. This study examined to assess possible associations between genital prolapse and the incidence of vaginal cancer.
\end{abstract}

Methods: We conducted a systematic literature search regarding the association between vaginal cancer and genital prolapse, supplemented with our own data set of the Centre for Gynaecological Oncology of the Ortenau Clinic Offenburg.

Results: Our case analysis of prolapse-associated vaginal carcinomas corresponds to a large extent with the total collective of vaginal carcinomas. The most frequent histological subtype was squamous cell carcinoma in $90 \%$. The median age of patients with genital prolapse-associated vaginal carcinomas was 75 years $(72.9 \pm 12.1$ years). However prolapse associated vaginal cancers had FIGO stage IV more often than cases of vaginal cancer in general. FIGO stage I was reported as most frequent (39\%). FIGO stage IV was the second most frequent stage in prolapse associated cases (25\%). Furthermore, the Kaplan-Meier curves are significantly different from unselected vaginal cancer cases. In the prolapse associated cases FIGO stages I and II have a far better disease-free survival; in contrast, the prognosis in the advanced stages is much worse.

Conclusion: In addition to the HPV infection, patients with genital prolapsed and those with ongoing systemic corticosteroid therapy or other immunocompromising medications, should be perceived as risk groups and regularly examined.

\section{Keywords}

Vaginal cancer, Vaginal carcinoma, Pessary, Genital prolapse

\section{Introduction}

Primary vaginal cancer represents a rare disease. For Germany, the relevant figures for this disease in 2014 were incidence approximately 1190 cases, mortality 456 cases, mean age at diagnosis 71 years and 5-year overall survival $52 \%$ [1]. The main histologic types of vaginal cancers are squamous cell cancers ( $>95 \%)$. Adenocarcinomas can be found in about $5-10 \%$ of the cases [2]. Clear cell carcinoma, which is associated with in utero exposition of diethylstilboestrol, represents an even rarer subtype of this tumour and is not found any more today [3].

The main risk factor for vaginal carcinoma is a persistent human papillomavirus (HPV) infection, and HPV type 16 is the most frequently encountered subtype [4]. Prior cervical dysplasia [5], immunosuppression (e.g., due to HIV infection or after organ transplant), which facilitates an HPV infection, and lichen sclerosus [6] can be regarded as risk factors.

However, chronic mechanic irritation of the vagina, for example, due to pessaries, has long been suspected to contribute to the development of vaginal cancer [7]. Although such correlations have been suspected since 1961, mainly case reports and small case series have been published so far, which have not been able to confirm or disprove it [8].

In order to assess possible associations between genital prolapse and the incidence of vaginal cancer, we analysed patient data at the Centre for Gynaecolog-

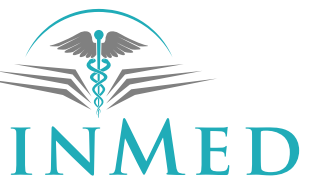

INTERNATIONAL LIBRARY

Citation: Männle H, Osorio B, Momm F, Münstedt K (2021) Is there an Association between Vaginal Cancer and Genital Prolapse? A Data-Analysis and Review of Literature. Int J Oncol Res 4:027. doi. org/10.23937/2643-4563/1710027

Accepted: March 11, 2021: Published: March 13, 2021

Copyright: (c) 2021 Männle $\mathrm{H}$, et al. This is an open-access article distributed under the terms of the Creative Commons Attribution License, which permits unrestricted use, distribution, and reproduction in any medium, provided the original author and source are credited. 
ical Oncology of the Ortenau Clinic Offenburg. We also wanted to supplement our cases with cases from the literature in accordance with earlier analyses of rare gynaecological tumour types $[9,10]$. Using a combined analysis of all available cases we intended to expand the current knowledge on vaginal carcinomas, especially those related to genital prolapse.

\section{Material and Methods}

All tumour patients at the Centre for Gynaecological Oncology of the Ortenau Clinic Offenburg are documented in our own tumour-documentation system GeDos. All patients were informed about this and gave their consent for the documentation and evaluation. A retrospective analysis of this data set revealed seven patients with primary vaginal carcinoma between 2010 and 2018. Four of them were in the context of genital prolapse.

\section{Search of literature}

We conducted a systematic search regarding the association between vaginal cancer and genital prolapse. All publications published until July 2019 were considered. The search in PubMed (Medline) was based on the keywords (A): Vaginal cancer or cancer of the vagina or vaginal neoplasia or vaginal carcinoma or carcinoma of (the) vagina, or carcinosarcoma of vagina or vaginal squamous cell carcinoma or adenocarcinoma of vagina; (B): Uterine prolapse or pelvic organ prolapse or genital descensus or uterovaginal prolapse or total prolapse or genital prolapse or prolapse; and (C): Pessary or vaginal pessary. $A$ and $B$ as well as $A$ and $C$ were linked by "AND" and afterwards by "OR". Use of further electronic medical data systems (Cochrane Library, Google scholar, Scopus and JUST find) complemented our search. In the second step, we analysed the references in all retrieved publications in order to identify further publications that might not have been found in the referred databases, which included meta-analyses and systematic reviews.

\section{Criteria for eligibility}

All publications that were identified in the first two steps were included if they could be retrieved as full text articles in the following languages: English, French, German and Spanish.

\section{Selection of publications}

Titles and abstracts of the retrieved publications were checked by the two authors of this study (HM, KM) for agreement with the criteria for eligibility. Publications which did not match them as well as double publications were excluded. Afterwards, the full texts of the included publications were analysed. Cases of patients with simultaneously occurring genital cancers were also excluded.

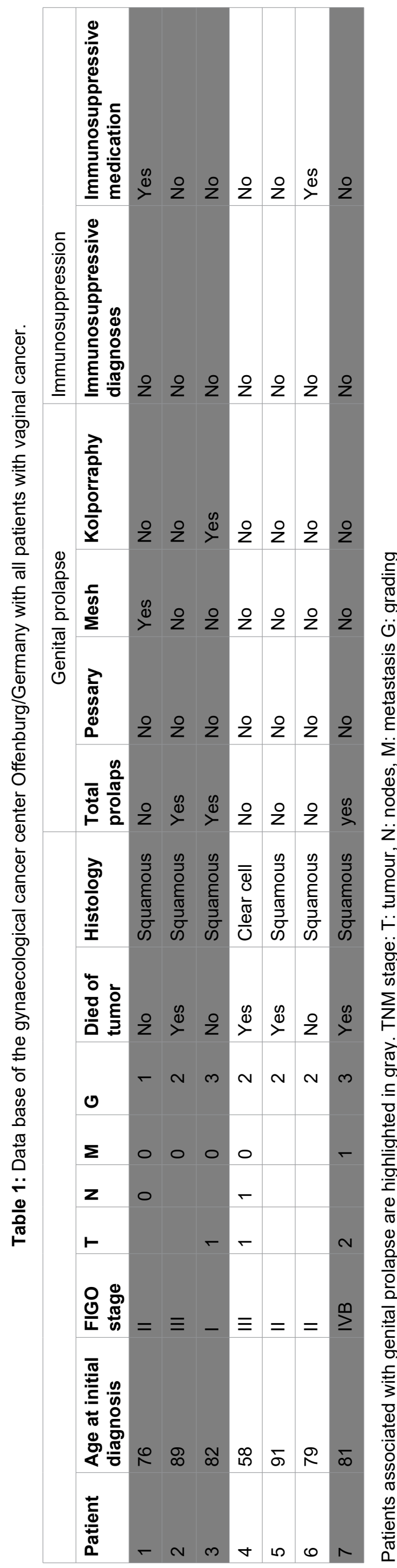




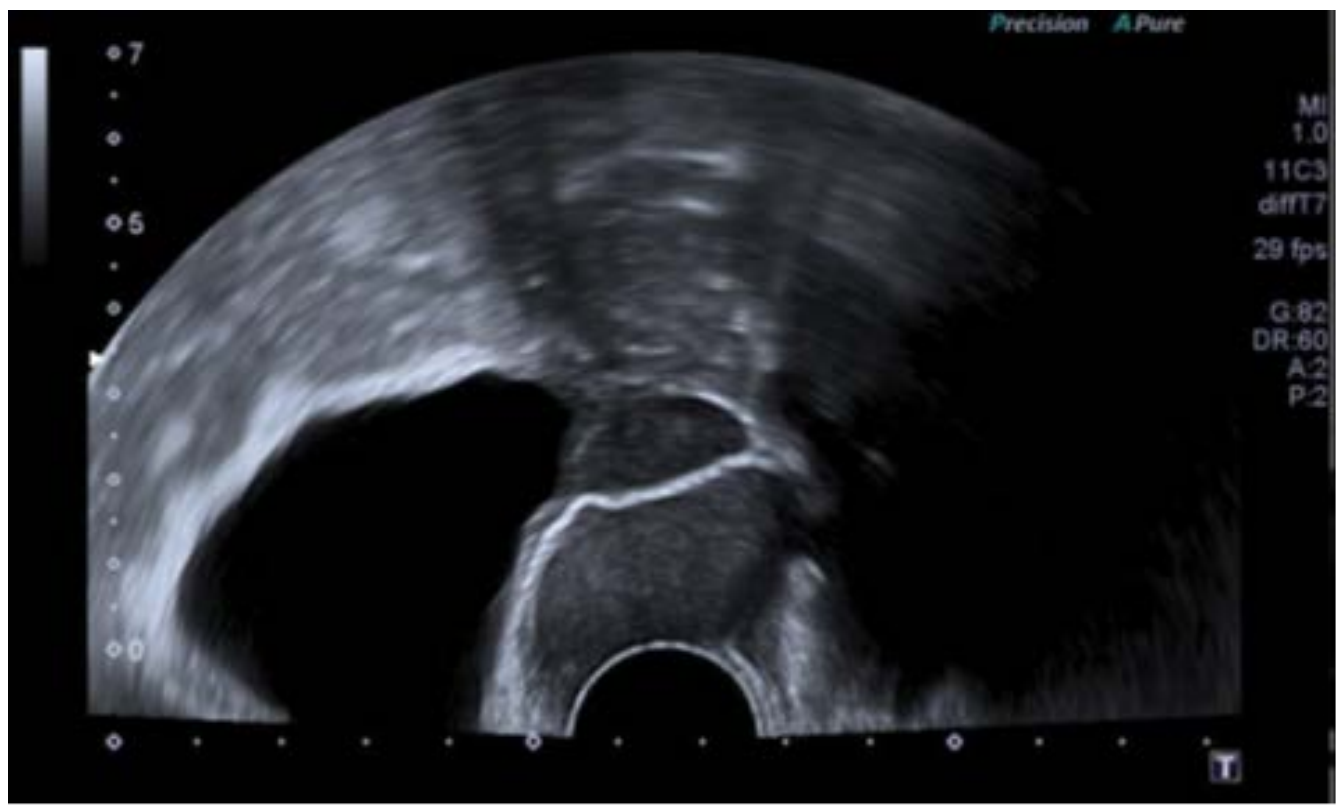

Figure 1: Transvaginal sonography: A $29 \times 37 \mathrm{~mm}$ moderately hyperechoic mass passing through the mesh.

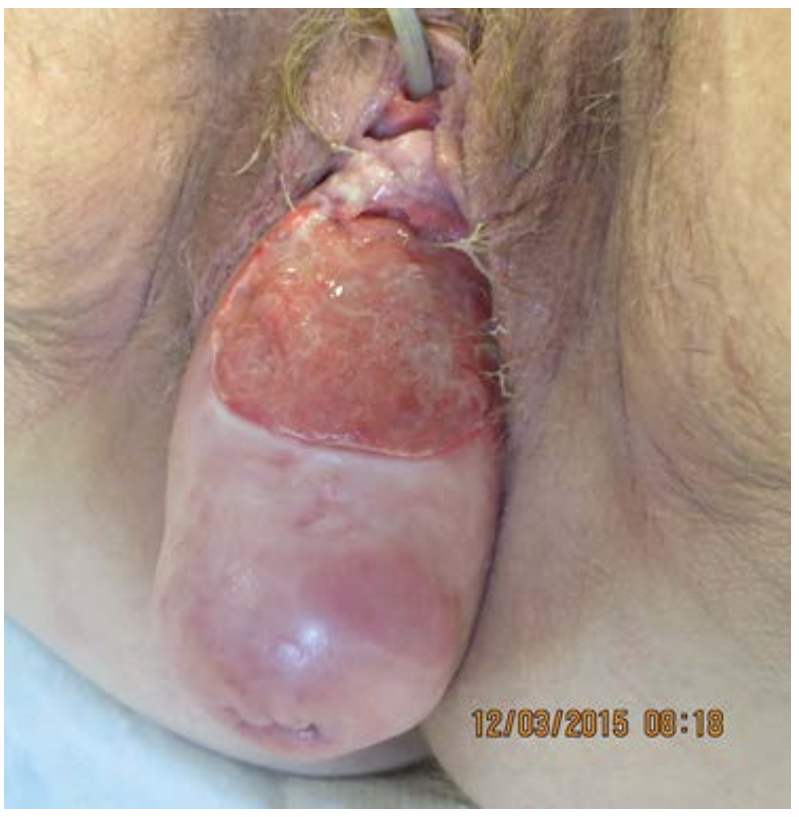

Figure 2: Total prolapse with ulceration on the anterior wall, histologically confirmed as squamous cell carcinoma.

\section{Data analyses}

Relevant data (author, year of publication, age at diagnosis, histology, FIGO stage, TNM stage, grading, observation period, tumour associated death (yes/no), primary treatment (radiotherapy or surgery), prolapse stage, use of pessaries, earlier treatment with vaginal synthetic mesh, prior urogynaecological surgery, concurrent immunosuppressive diseases or treatments) were assessed in a table.

\section{Ethics}

We obtained positive consent from the Ethics Committee of the Medical Faculty of the University of Freiburg i.Br (No. 5/20).

\section{Data management and statistical analyses}

We used SPSS for Windows (version 11.5) for statistical data analyses, which included descriptive and analytical methods as well as survival analyses (Kaplan-Meier curves and log-rank tests). A p-value of 0.05 was considered significant.

\section{Results}

\section{Database of the gynaecological cancer centre Of- fenburg/Germany}

Table 1 provides an overview of the main characteristics of our patients with vaginal cancer. Six out of seven $(86 \%)$ of our patients had squamous cell carcinomas. Unfortunately, no HPV testing was done at the time of diagnosis. One case (14\%) presented as an adenocarcinoma, namely a clear cell carcinoma.

Table 1 shows that, among patients with squamous cell carcinomas, urogynaecological problems were found in four cases. Interestingly, three out of six patients (50\%) had pronounced genital prolapse. One case of squamous cell carcinoma occurred after transvaginal mesh surgery (16.6\%). Figure 1 shows the transvaginal sonographie (TVS) with a $29 \times 37 \mathrm{~mm}$ moderately hyperechoic mass passing through the mesh with pronounced vascularization. Figure 2 shows exemplary a total prolapse with ulceration on the anterior wall, histologically confirmed as squamous cell carcinoma.

\section{Systematic literature search}

The initial search strategy in the medical databases and the associated hand search yielded 719 titles. As shown in Figure 3 (search strategy flow chart), most items were excluded due to duplicate records or misleading titles. Another exclusion was made, because they were not suitable for data analyses (e.g., because 

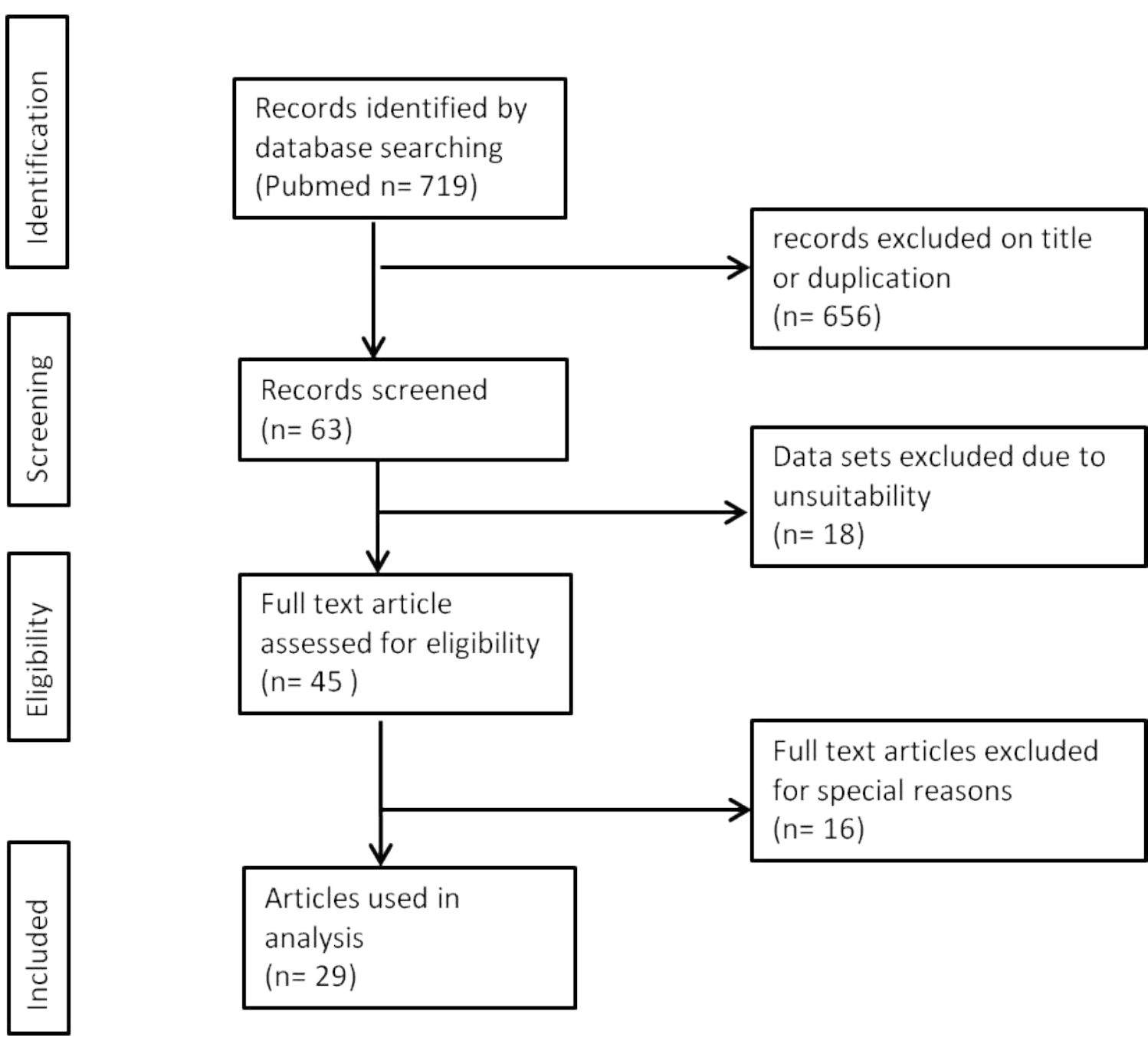

Full text article assessed for eligibility $(n=45)$

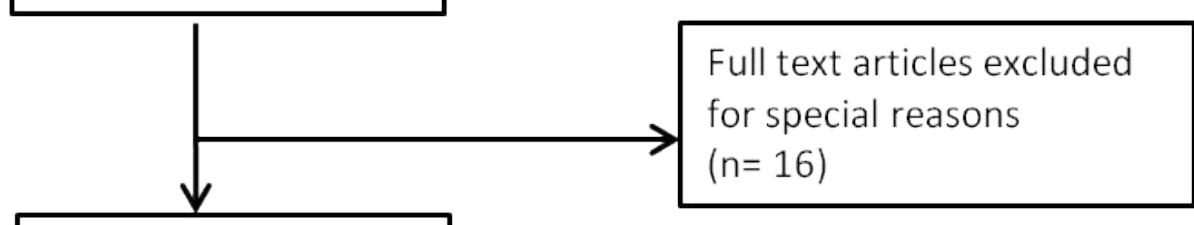

Articles used in analysis

$(n=29)$

Figure 3: Search strategy for this systematic review.

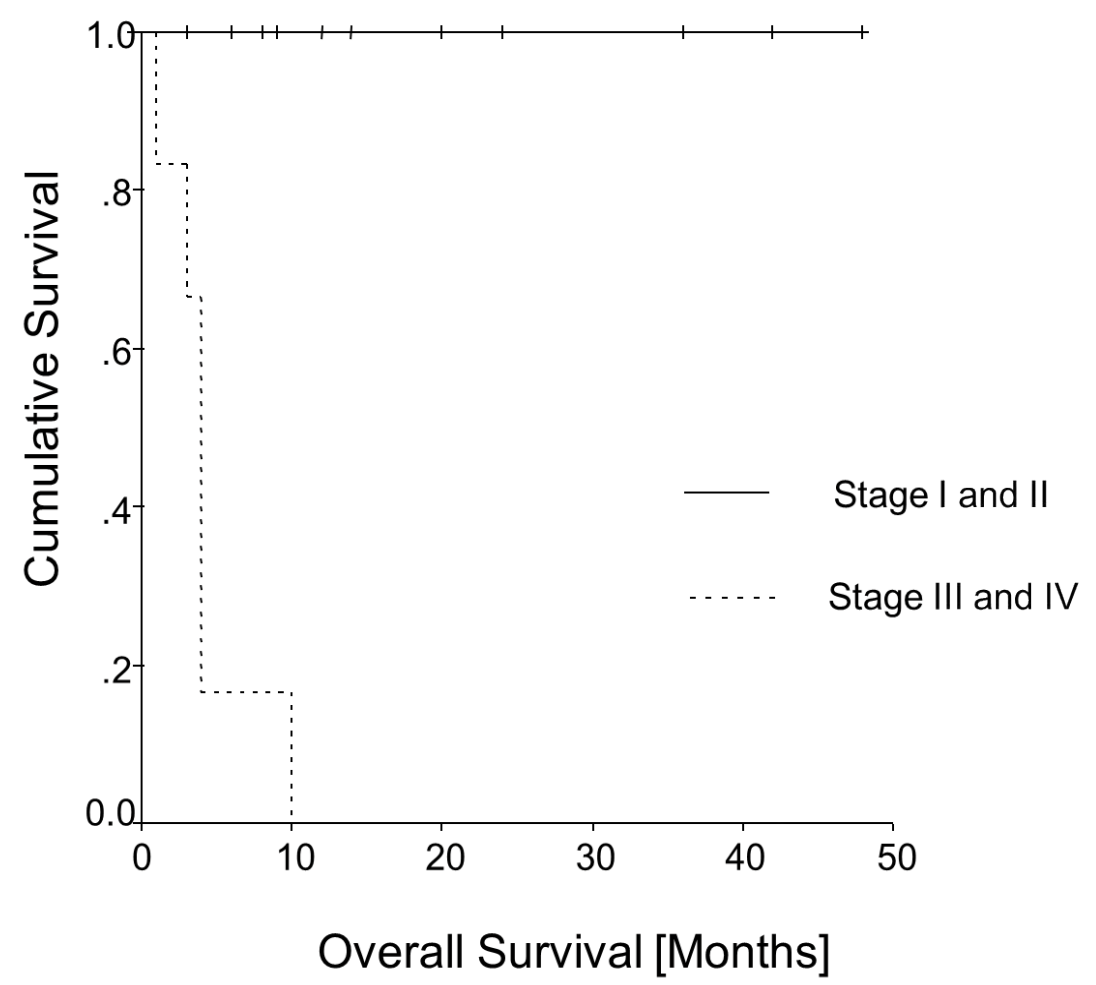

Figure 4: Kaplan-Meier curve: Overall survival. 
of second malignancies). All 45 articles that met the eligibility criteria were fully read. Among these, 29 met the admission criteria.

The data of all patients were combined in a joined table. Table 2 summarizes the main data from the literature review of vaginal cancers associated with genital prolapse that were reported up to July 2019. The table also includes the patients from the Offenburg collective with genital prolapse associated vaginal cancer (4 cases).

The median age of the patients was 75 years (mean $72.9 \pm 12.06$ years; range 46 to 96 years). In the synopsis of all the data on the topic, there was an association between pessary therapy and vaginal cancer in almost one-third of the cases (14 out of $45 ; 31.1 \%$ ). The most frequent histological subtype was squamous cell carcinoma (35 out of $39 ; 90 \%$ ).

In all, 39\% (11 of 28) of patients were FIGO stage I. The next most frequent stages were FIGO stage IV $(25 \%$; 7 out of 28$)$, stage II ( $21 \%$; 6 out of 28 ) and stage III (14\%; 4 out of 28).

Figures 4 and Figure 5 show the Kaplan-Meier curves of all patients of Table 2 for overall survival and disease-free survival as a function of the FIGO stages. Both curves have statistical significance for overall survival ( $p$ $=0.0001$; log rank $=18.98, \mathrm{df}=2$ ) and for disease-free survival $(p=0.0003 ;$ log rank $=16.51, d f=2)$.

\section{Discussion}

The hypothesis regarding associations between the occurrence of primary squamous cell carcinoma of the vagina and urogynaecological problems, in particular genital total prolapse, has been discussed for many years. It is supported by this study. Whether there is a causal connection or only a correlation cannot be elucidated. As shown, our database at the Ortenau Clinic Offenburg revealed four out of six patients (66\%) with squamous cell carcinoma having a corresponding association. This study supports the findings of a case series by Rao, et al. (1989), who showed that in six out of 11 cases ( $55 \%)$, there was an association between vaginal carcinoma and genital prolapse [11]. Another case series of nine cases established a possible association between the use of pessaries and vaginal carcinomas. Ring pessaries in particular seem to be problematic [12]. However, further case reports of single cases did not allow any conclusion on the referred association, since they were not related to the population of all vaginal carcinomas $[7,8,13]$.

Considering that conditions with chronic irritation, including lichen sclerosus, are known risk factors for the development of vaginal carcinoma [6], it is not surprising that there could be an association with genital prolapse. Due to the dryness and irritability of the prolapsed vagina or mechanical irritation caused by pessaries, it may be more susceptible to carcinogenesis induced by HPV. Unfortunately, Shah, et al. (2009) did not consider genital prolapse as a potential risk factor in their analysis of 2149 cases of primary vaginal carcinoma [14].

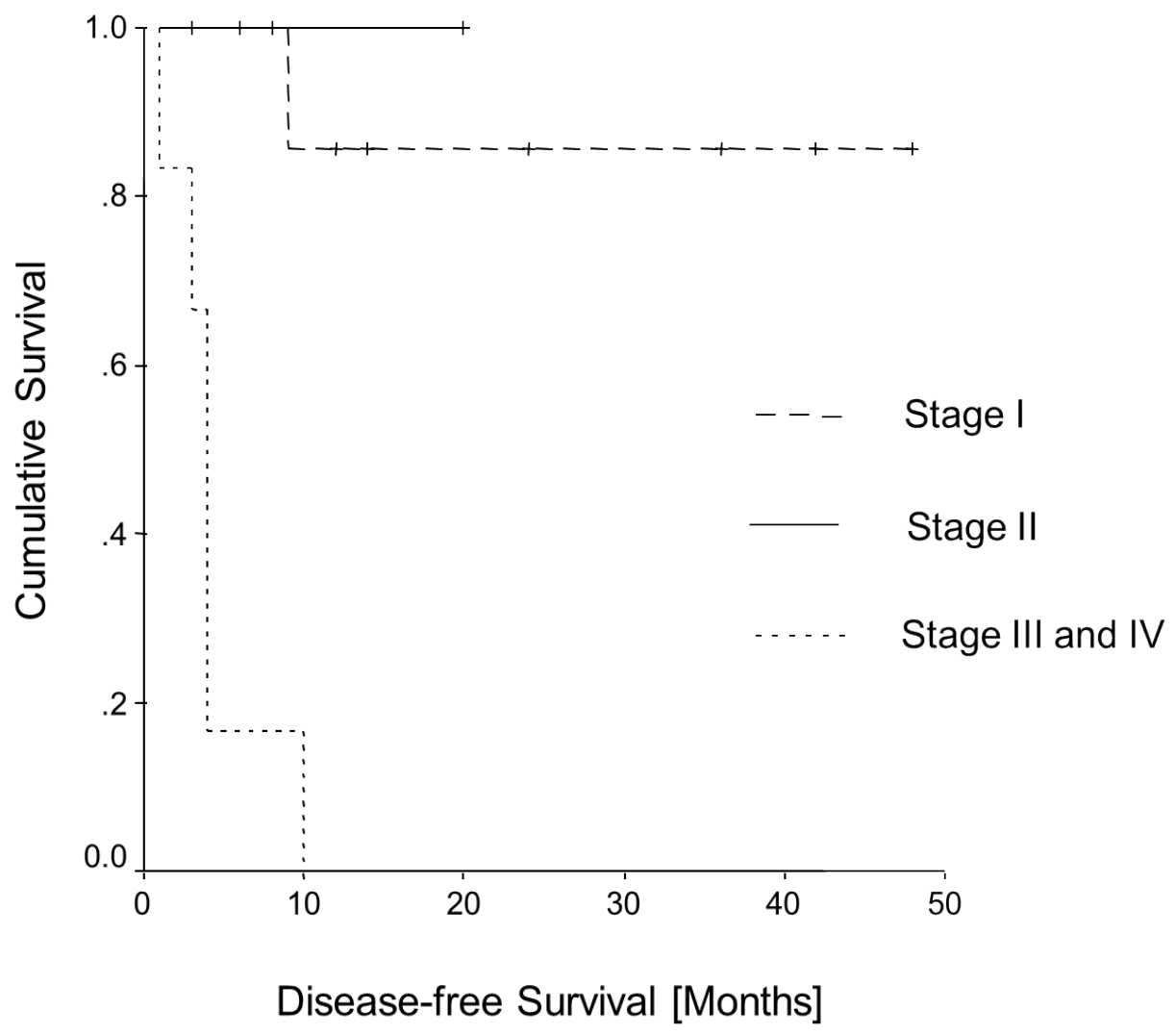

Figure 5: Kaplan-Meier curve: Disease-free survival. 
Demographic data of our case analysis of prolapse-associated vaginal carcinomas with a total of 45 cases, found in the literature search corresponds well to the total collective of vaginal carcinomas in Germany as published by the Robert Koch Institute [1]. The median age of patients with genital prolapse-associated vaginal carcinomas was 75 years (72.9 \pm 12.1 years). Also the most frequent histological subtype was squamous cell carcinoma in $90 \%$ (35 out of 39 ).

On the other hand, there are differences with regard to the FIGO stage. In the annual FIGO report a decreasing frequency of higher FIGO stages is shown. Similar to our analysis, FIGO stage I was the most frequent stage in $39 \%$ (11 out of 28 ), however FIGO stage IV was the second most frequently found stage in $25 \%$ ( 7 out of 28 ) and therefore much more frequently found than usual. Stage II at $21 \%$ and stage III at $14 \%$ were roughly in line the decreasing frequency.

This showed that patients with genital prolapse compared to unselected patients with vaginal carcinoma next to the early-stage (FIGO stage I) frequently had a higher stage (FIGO stage IV). This could have different causes. It can be assumed that genital inspection with correspondingly prolapsed vaginal walls could make early diagnosis more difficult. It can be assumed that the most obvious explanation, that the two conditions (severe prolapse and vaginal cancer) share many risk factors (age, poor attention for their intimacy) and that these women may no longer be so conscientious with regular screening; thus, the diagnosis was delayed.

Also it seems that patients in our analysis in tumour stages I and II did not die from the disease. On the other hand, the patients with advanced disease (stages III and IV) seem to have had a much worse prognosis, since all died within 10 months.

The older age of patients in our collective could be the underlying reason for this. Because of the high age, the likelihood of non-cancer-related death was higher, leading to the very good survival curves for stages I and II when it comes to cancer-associated death. On the other hand, old age may often not allow standard treatment in advanced stages, so patients are more likely to die from cancer. This concept underlines the importance of assessing the whole situation of patients before recommending therapy. In particular, the personal life expectancy of the patient should be considered. This could be done using the Charlson Comorbidity Index. Thus, some patients could be spared a stressful therapy if there is no benefit of treatment.

It is noticeable that one of our patients had surgery with the insertion of vaginal mesh. Perhaps, this contributed to the development of the cancer because of mechanical irritation and a possible way for HPV to enter the deeper cell layers. However, a systematic review by Adel, et al. [15] concluded that the likelihood of polypropylene mesh causing malignancy is very low.
Other authors found no significant association between polypropylene mesh and the development of malignancy. However, short follow-up periods of about 5 years did not allow a final conclusion $[16,17]$. Further surveys with longer follow-up times would be desirable.

In cases of immunosuppression (e.g., due to HIV infection or immunosuppressive medication after organ transplantation), HPV infection may be an important risk factor. Akino reported the case of a patient with pessary therapy who was systemically treated with prednisolone due to interstitial pneumonia and subsequently developed primary vaginal carcinoma [18]. An HPV test was negative. Two of our patients were systemically treated with a corticosteroid (prednisone and prednisolone) for bronchial asthma. There are numerous diseases that make immunosuppressive medication necessary, such as inflammatory bowel diseases, chronic obstructive pulmonary diseases or rheumatic diseases. Vuitton, et al. [19] was able to show in a study that HPV infection of the anal canal was present in a third of the patients who underwent coloscopy. Almost $20 \%$ of the cases were found to be infected with high-risk HPV, and this was significantly higher in Crohn's disease patients. In women with chronic inflammatory bowel diseases (IBD) a conspicuous Pap smear was increasingly detected. Compared to healthy controls, the incidence was $42.5 \%$ versus $7 \%$ ( $p<0.001)$, and higher-grade lesions were also more common ( $p<0.001)$. Women with a history of immunosuppressive therapy were more likely to have an abnormal Pap smear ( $p<0.001$ ) than control subjects; immunosuppressive therapy for $>6$ months increased the risk of OR $1.5(1.2-4.1, p=0.021)$ [20].

Merino described various factors that appear to influence the development of vaginal carcinomas. These include chronic pessary irritation, previous hysterectomy for benign disease, immunosuppressive therapy, cervical irradiation and endometriosis $[19,21]$. It can be assumed that the interaction of different risk factors increases the risk of developing vaginal carcinoma.

The above findings lead to the conclusion that not only the HPV infection but also chronic irritation must be taken seriously as a risk factor. In particular patients with genital prolapse, especially those treated with pessaries and those with ongoing systemic corticosteroid therapy or other immunocompromising medications, should be regularly examined. Our findings emphasize the necessity for regular gynaecological check-ups (e.g., during pessary changes). Symptoms like bleeding or malodorous discharge should entail biopsy.

Acknowledging the continuously increasing life expectancy and an aging general population as well as the associated increase in genital prolapse, it seems necessary to analyse the problems addressed in this study in prospective data collections, especially chronic diseases that require medication with corticosteroids should be examined to be an additional risk factor. 


\section{Conclusions}

Genital prolapse should be recognized as a risk factor for vaginal cancer. However, this study cannot prove such an association and would require a better adapted, well-designed study. We believe that the diagnosis of vaginal cancer can be delayed by difficult examination conditions and it can be assumed that this risk group avoids regular gynecological controls.

Chronic diseases that require corticosteroid medication appear to increase the risk. Squamous cell carcinomas are the dominant histological subtype in genital prolapse-associated vaginal carcinoma. Also, the mean age of patients is similar to the "normal" vaginal cancer. However, FIGO stage IV is more common if the vaginal cancer is associated with genital prolapse, which is believed based on the delayed diagnosis. Regular gynaecological check-ups for patients with genital prolapse should be mandatory for better early detection of tissue alterations. Also, patients must be informed about the relevant symptoms and asked to see a physician when they become apparent.

\section{Acknowledgements}

We thank all the people who contributed to the establishment and maintenance of our databank on gynaecological cancer. This includes our tumour documenters - namely, Mrs. Andrea Heuberger - as well as all gynaecologists and general practitioners in our region who informed us about the follow-up of the patients. We would especially like to thank Mr. Alexander Schattenberg, who developed the GeDos documentation system and was always ready to assist us with special queries.

\section{Sources of Support}

This research did not receive any specific grant from funding agencies in the public, commercial, or not-forprofit sectors.

\section{Statement of Equal Authors' Contribution}

Dr. Heidrun Männle: Original idea, planning, and input of the manuscript, Data collection, Analysis and interpretation of data, Writing the manuscript.

Dr. Birthe Osorio: Reading/commenting/editing of manuscript, Critical revision of the manuscript.

Prof. Dr. Felix Momm: Reading/commenting/editing of manuscript, Critical revision of the manuscript.

Prof. Dr. Karsten Münstedt: Reading/commenting/ editing of manuscript, Critical revision of the manuscript, Supervision of the study/manuscript, Training/ education of authors, Mentoring of $1^{\text {st }}$ author, Statistical Expertise.

\section{References}

1. Robert Koch Institut (2017) Zentrum für Krebsregisterdaten.
2. Rajaram S, Maheshwari A, Srivastava A (2015) Staging for vaginal cancer. Best Pract Res Clin Obstet Gynaecol 29: 822-832.

3. Robboy SJ, Young RH, Welch WR, Truslow GY, Prat J, et al. (1984) Atypical vaginal adenosis and cervical ectropion. Association with clear cell adenocarcinoma in diethylstilbestrol-exposed offspring. Cancer 54: 869-875.

4. Alemany L, Saunier M, Tinoco L, Quirós B, Alvarado-Cabrero I, et al. (2014) HPV VVAP study group. Large contribution of human papillomavirus in vaginal neoplastic lesions: a worldwide study in 597 samples. Eur J Cancer 50: 28462854.

5. Strander B, Andersson-Ellström A, Milsom I, Spa (2007) Long term risk of invasive cancer after treatment for cervical intraepithelial neoplasia grade 3: population based cohort study. BMJ 335: 1077.

6. Halonen P, Jakobsson M, Heikinheimo O, Riska A, Gissler $\mathrm{M}$, et al. (2017) Lichen sclerosus and risk of cancer. Int J Cancer 140: 1998-2002.

7. Jain A, Majoko F, Freites $O$ (2006) How innocent is the vaginal pessary? Two cases of vaginal cancer associated with pessary use. J Obstet Gynaecol 26: 829-830.

8. Russell JK (1961) The dangerous vaginal pessary. Br Med J 2: 1595-1597.

9. Hackethal A, Brueggmann D, Bohlmann MK, Franke FE, Tinneberg HR, et al. (2008) Squamous-cell carcinoma in mature cystic teratoma of the ovary: systematic review and analysis of published data. Lancet Oncol 9: 1173-1180.

10. Münstedt K, Estel R, Dreyer T, Kurata A, Benz A (2013) Small Cell Ovarian Carcinomas - Characterisation of Two Rare Tumor Entities. Geburtshilfe Frauenheilkd 73: 698704.

11. Rao K, Kumar NP, Geetha AS (1989) Primary carcinoma of vagina with uterine prolapse. J Indian Med Assoc 87: 10-12.

12. Abdulaziz M, Stothers L, Lazare D, Macnab A (2015) An integrative review and severity classification of complications related to pessary use in the treatment of female pelvic organ prolapse. Can Urol Assoc J 9: E400-E406.

13. Fedus T, Raś R, Książek M, Filipowska J, Kaznowska E, et al. (2017) Primary vaginal squamous cell carcinoma with bladder involvement in uterine prolapsed patient: Case report. Medicine (Baltimore) 96: e8993.

14. Shah CA, Goff BA, Lowe K, Peters WA 3rd, Li Cl (2009) Factors Affecting Risk of Mortality in Women With Vaginal Cancer. Obstet Gynecol 113: 1038-1045.

15. Adel E, Shapiro R, Zaslau S (2017) Carcinogenic potential of polypropylene mid-urethral slings: What do we know so far? International Urogynecology Journal 28: 657-660.

16. Altman D, Rogers RG, Yin L, Tamussino K, Ye W, et al. (2018) Cancer Risk After Midurethral Sling Surgery Using Polypropylene Mesh. Obstet Gynecol 131: 469-474.

17. Linder BJ, Trabuco EC, Carranza DA, Gebhart JB, Klingele CJ, et al. (2016) Evaluation of the local carcinogenic potential of mesh used in the treatment of female stress urinary incontinence. Int Urogynecol J 27: 1333-1336.

18. Akino N, Wada-Hiraike O, Matsumoto $\mathrm{Y}$, Arimoto $\mathrm{T}$, Oda $\mathrm{K}$, et al. (2016) Vaginal cancer possibly caused by pessary and immunocompromised condition: Multiple risk factors may influence vaginal cancer development. J Obstet Gynaecol Res 42: 748-751. 
19. Vuitton L, Jacquin E, Parmentier AL, Crochet E, Fein F, et al. (2018) High Prevalence of Anal Canal High-Risk Human Papillomavirus Infection in Patients With Crohn's Disease. Clin Gastroenterol Hepatol 16: 1768-1776.

20. Kane S, Khatibi B, Reddy D (2008) Higher incidence of abnormal Pap smears in women with inflammatory bowe disease. Am J Gastroenterol 103: 631-636.

21. Merino MJ (1991) Vaginal cancer: The role of infectious and environmental factors. Am J Obstet Gynecol 165: $1255-1262$.

22. Ishibashi N, Maebayashi T, Asai M, Kawana K, Okada M (2019) Radiation therapy for vaginal cancer in complete uterine prolapse with intrauterine adhesion: a case report. BMC Womens Health 19: 69.

23. Babarović E, Sladoljev K, Perin E, Klarić M, Karnjuš-Begonja R, et al. (2018) Primary Carcinosarcoma of the Vagina Associated With Differentiated Squamous Intraepithelial Neoplasia in a Patient With Complete Uterine Prolapse: Case Report and Review of the Literature. Int J Surg Pathol 26: 370-376.

24. Sonkusare S, Shetty VJ, Harikumar S, Harikumara S, Murthi P, et al. (2016) Primary vaginal cancer complicating massive uterine prolapse: A case report. J Cases Obstet Gynecol 3: 92-95.

25. Kowalski J, Savage J, Bradley CS (2015) Vaginal cancer in patient presenting with advanced pelvic organ prolapse: case report and literature review. Proc Obstet Gynecol 5: 3.

26. Wang Y, Li Q, Du H, Lv S, Liu H (2014) Uterine prolapse complicated by vaginal cancer: a case report and literature review. Gynecol Obstet Invest 77: 141-144.

27. Moszyński R, Kościński T, Burchar B (2014) Squamous cell vaginal cancer in a patient with complete pelvic organ prolapse. Curr. Gynecol. Oncol 12: 233-238.

28. Kim HG, Song YJ, Jin Y, Choi OH (2013) A case of vaginal cancer with uterine prolapse. J Menopausal Med 19: 139-142.

29. Begum S, Akhter R, Begum K (2013) Primary vaginal carcinoma, tales of tragedy: case report. Chattagram Maa-OShishu Hospital Med Coll J 12: 64-66.

30. Kumar V, Ratna B (2013) Primary vaginal carcinoma of lower one-third of posterior vagina associated with third-degree prolapse: a rare case. J Obstet Gynecol India 63: 356-358.

31. Martin C, Hong L, Siddighi S (2013) What is hiding behind the pessary? Int Urogynecol J 24: 873-875.

32. Acharya S, Uprety DK (2012) Carcinoma of vagina in utero-vaginal prolapse: a rare presentation. JNMA J Nepal Med Assoc 52: 82-84.
33. Cho MK, Kim CH, Kim YH (2011) Primary invasive carcinoma of the vagina after Le Fort partial colpocleisis for stage IV pelvic organ prolapse: a case report. Int Urogynecol J 22: 1459-1461.

34. Batista TP, Morais JA, Reis TJ, Bulcão Macedo FI (2009) A rare case of invasive vaginal carcinoma associated with vaginal prolapse. Arch Gynecol Obstet 280: 845-848.

35. Ghosh SB, Tripathi R, Mala YM, Khurana N (2009) Primary invasive carcinoma of vagina with third degree uterovaginal prolapse: a case report and review of literature. Arch Gynecol Obstet 279: 91-93.

36. Gupta N, Mittal S, Dalmia S, Misra R (2007) A rare case of primary invasive carcinoma of vagina associated with irreducible third degree uterovaginal prolapse. Arch Gynecol Obstet 276: 563-564.

37. lavazzo C, Vorgias G, Vecchini G, Katsoulis M, Akrivos T (2007) Vaginal carcinoma in a completely prolapsed uterus. A case report. Arch Gynecol Obstet 275: 503-505.

38. Karateke A, Tugrul S, Yakut Y, Gürbüz A, Cam C (2006) Managment of case of primary vaginal cancer with irreducible massive uterine prolapse: a case report. Eur J Gynaecol Oncol 27: 528-530.

39. Meier HM, Schopohl B (1995) Extensive vaginal carcinoma with total prolapse -- a therapeutic problem. Zentralbl Gynakol 117: 160-163.

40. Bastidas BS, Alvarado CA, Garcia BLM (1989) Primary invasive carcinoma of the vagina and $3 d$ degree genital prolapse. Presentation of a case. Ginecol Obstet Mex 57: 305-307.

41. Howat JM, Stassan L, Mohandas I, Daw E (1984) Carcinoma of the vagina presenting as a ruptured procidentia with an entero-vaginalfistula and prolapse of the small bowel. Postgraduate Medical Journal 60: 435-436.

42. Gautier P, Desmons F, Fichelle (1971) 2 cases of vaginal cancers caused by pessaries (apropos of 2 cases). Bull Fed Soc Gynecol Obstet Lang Fr 23: 298-299.

43. Amalric R, Heftman M, Ayme Y, Spitalier JM (1970) Cervico-vaginal carcinoma and pessary: A further characteristic case. Bull Fed Soc Gynecol Obstet Lang Fr 22: 308-309.

44. Lamotte $G$ (1969) Primary adenocarcinoma of the vagina due to the use of a pessary. Bull Soc R Belge Gynecol Obstet 39: 287-294.

45. Berthelsen HG (1957) Vaginal carcinoma associated with total prolapse; report of a case. Acta Obstet Gynecol Scand 36: $257-261$. 